\title{
TRPA1 Channels Are Regulators of Astrocyte Basal Calcium Levels and Long-Term Potentiation via Constitutive D-Serine Release
}

\author{
Eiji Shigetomi, ${ }^{1 \star}$ Olan Jackson-Weaver, ${ }^{1 \star}$ Robert T. Huckstepp, ${ }^{2}$ Thomas J. O’Dell, ${ }^{1}$ and Baljit S. Khakh ${ }^{1,2}$ \\ ${ }^{1}$ Departments of Physiology and ${ }^{2}$ Neurobiology, David Geffen School of Medicine, University of California Los Angeles, Los Angeles, California 90095
}

Astrocytes are found throughout the brain where they make extensive contacts with neurons and synapses. Astrocytes are known to display intracellular $\mathrm{Ca}^{2+}$ signals and release signaling molecules such as $\mathrm{D}$-serine into the extracellular space. However, the role(s) of astrocyte $\mathrm{Ca}^{2+}$ signals in hippocampal long-term potentiation (LTP), a form of synaptic plasticity involved in learning and memory, remains unclear. Here, we explored a recently discovered novel TRPA1 channel-mediated transmembrane $\mathrm{Ca}^{2+}$ flux pathway in astrocytes. Specifically, we determined whether block or genetic deletion of TRPA1 channels affected LTP of Schaffer collateral to CA1 pyramidal neuron synapses. Using pharmacology, $T R P A 1^{-1-}$ mice, imaging, electrophysiology, and D-serine biosensors, our data indicate that astrocyte TRPA1 channels contribute to basal $\mathrm{Ca}^{2+}$ levels and are required for constitutive D-serine release into the extracellular space, which contributes to NMDA receptor-dependent LTP. The findings have broad relevance for the study of astrocyte-neuron interactions by demonstrating how TRPA1 channel-mediated fluxes contribute to astrocyte basal $\mathrm{Ca}^{2+}$ levels and neuronal function via constitutive D-serine release.

\section{Introduction}

Astrocytes are found throughout the brain and their close proximity and contact with neurons has been known for over a century (DeFelipe, 2010). More recent anatomical studies show that single astrocytes have nonoverlapping territories encompassing thousands of synapses (Bushong et al., 2002; Halassa et al., 2007), and electron microscopy shows that $57 \%$ of all excitatory synapses in the stratum radiatum region of the hippocampus are adjacent to astrocyte processes (Ventura and Harris, 1999). Thus, astrocytes are an important part of neuronal networks, where they serve homeostatic roles, contribute to synapse formation, respond to neuronal excitation, and regulate neuronal function (Barres, 2008; Halassa and Haydon, 2010). However, our understanding is still incomplete and several fundamental questions remain open, including if/how astrocyte $\mathrm{Ca}^{2+}$ signals contribute to synaptic plasticity.

Received Dec. 17, 2012; revised April 29, 2013; accepted May 2, 2013

Author contributions: E.S., R.T.H., T.J.O., and B.S.K. designed research; E.S., O.J.-W., and T.J.0. performed research; R.T,H. contributed unpublished reagents/analytic tools; E.S., 0.J.-W., T.J.0., and B.S.K. analyzed data; E.S. and B.S.K. wrote the paper.

This work was supported by the Whitehall Foundation, the National Institutes of Health (NS071292, NS060677), a Stein/Oppenheimer Endowment Award, and partly by the CHDI Foundation (B.S.K.). 0.J.-W. was supported by T32 NS007101. Thanks to Michael V. Sofroniew for sharing equipment. We thank Erin Gray for guidance with the LTP experiments and Drs. M. Haustein and X. Tong for valuable comments and discussions. Many thanks to Mary Hamby for guidance with the RT-PCR experiments.

*E.S. and $0 . J .-W$. contributed equally to this work.

Correspondence should be addressed to either of the following: Baljit S. Khakh, Department of Physiology, University of California, Los Angeles, 10833 Le Conte Avenue, 53-263 CHS, Los Angeles, CA 90095-1751, E-mail: bkhakh@mednet.ucla.edu, or Thomas J. O'Dell, Department of Physiology, David Geffen School of Medicine, University of California Los Angeles, Los Angeles CA 90095, E-mail: todell@mednet.ucla.edu.

E. Shigetomi's present address: Department of Pharmacology, Interdisciplinary Graduate School of Medicine and Engineering, University of Yamanashi, Chuo, Yamanashi 409-3898, Japan.

DOI:10.1523/JNEUROSCI.5779-12.2013

Copyright $\odot 2013$ the authors $\quad 0270-6474 / 13 / 3310143-11 \$ 15.00 / 0$
Pioneering studies showed that astrocytes synthesize, contain, and release D-serine (Hashimoto et al., 1993; Schell et al., 1995, 1997; Wolosker et al., 1999; Mothet et al., 2000). Later, D-serine was shown to be required for LTP because of its coagonist actions at the "glycine site" of NMDA receptors (NMDAR; Yang et al., 2003). Subsequent studies also showed that astrocyte-derived D-serine regulated LTP within the hippocampus in situ (Basu et al., 2009; Henneberger et al., 2010) by selectively targeting synaptic NMDARs (Papouin et al., 2012) and that a D-serinedependent form of cortical plasticity occurred in vivo (Takata et al., 2011). Of note, three studies highlighted the potential importance of hippocampal astrocyte $\mathrm{Ca}^{2+}$ signaling in regulating D-serine release and long-term potentiation (LTP; Mothet et al., 2000; Henneberger et al., 2010; Kang et al., 2013). In contrast, a separate study demonstrated that the deletion of IP3 type 2 receptors (IP3R2) abolished $\mathrm{Ca}^{2+}$ elevations mediated by intracellular stores, but had no effect on hippocampal LTP (Agulhon et al., 2010). At first sight, these studies seem contradictory (Kirchhoff, 2010), but perhaps a deliberated interpretation is warranted, because abolishing store-mediated $\mathrm{Ca}^{2+}$ release is not the same physiologically or biophysically as chelating $\mathrm{Ca}^{2+}$ with organic $\mathrm{Ca}^{2+}$ buffers, especially since astrocytes contain multiple $\mathrm{Ca}^{2+}$ sources (Nedergaard and Verkhratsky, 2012). From this perspective the recent discovery of TRPA1 channels as mediating a transmembrane $\mathrm{Ca}^{2+}$ flux pathway that (1) is independent of intracellular stores and (2) contributes to free basal $\mathrm{Ca}^{2+}$ levels in stratum radiatum region astrocytes (Shigetomi et al., 2012) provided a unique opportunity to explore if this novel pathway contributes to LTP (for review, see Clarke and Attwell, 2012; Tong et al., 2013; Scimemi, 2013). Recently these studies have been extended to show that hippocampal astrocytes display TRPA1 responses and express TRPA1 mRNAs (Nagai et al., 2004; Kimura 
et al., 2013). Moreover, TRPA1 proteins have been localized to astrocyte processes by immunogold electron microscopy (Lee et al., 2012). Thus, the possible role(s) of TRPA1 channels in LTP is an important issue to address, because stratum radiatum region astrocytes express TRPA1 channels, and also have the highest content of D-serine in relation to other regions of the brain (Schell et al., 1995, 1997). Additionally, the mechanisms that regulate D-serine release from astrocytes are not fully explored or completely understood (Oliet and Mothet, 2006, 2009).

\section{Materials and Methods}

Wild-type and mutant mice. Homozygous TRPA1 $1^{-1-}$ mice (Kwan et al., 2006; Shigetomi et al., 2012) backcrossed onto a C57BL/6J background were a gift from Dr. David P. Corey (Harvard Medical School, Boston, MA). The backcrossed TRPA1 $1^{-1-}$ mice were maintained as homozygotes: control mice for comparisons were C57BL/6J. Heterozygous $I P 3 R 2^{-/-}$mice (Li et al., 2005) were a gift from Dr. Ju Chen (University of California San Diego, La Jolla, CA). The IP3R2 ${ }^{-1-}$ mice were maintained as heterozygotes. Homozygotes and their wild-type (WT) littermates were used.

Reverse transcription PCR analysis of TRPA1 transcripts in purified astrocyte cultures. Purified astrocytes were prepared as previously described in detail (Shigetomi and Khakh, 2009; Shigetomi et al., 2010, 2012). Total RNAs were extracted from cultured astrocytes using the RNeasy Mini kit (Qiagen) with QIAshredder (Qiagen) according to the manufacturer's protocols. Reverse transcription (RT) was performed at $40^{\circ} \mathrm{C}$ for $60 \mathrm{~min}$ in a reaction volume of $25 \mu$ l containing $500 \mathrm{ng}$ of total RNAs, $5 \times$ First-Strand Buffer (Invitrogen), $0.5 \mu \mathrm{g}$ oligo (dT) (Invitrogen), $200 \mu \mathrm{M}$ dNTP mix (Ambion), nuclease free water (Ambion), and $200 \mathrm{U}$ M-MLV Reverse Transcriptase (Invitrogen). PCR amplification was performed in a reaction volume of $50 \mu$ l containing $10 \times$ PCR buffer, $5 \times$ Q solution, $250 \mu \mathrm{M}$ dNTPs, $1 \mu \mathrm{M}$ each of forward and reverse primers, and $2.5 \mathrm{U}$ TaqDNA polymerase (Qiagen). PCR amplification included denaturation at $95^{\circ} \mathrm{C}$ for $5 \mathrm{~min}, 35$ cycles at $95^{\circ} \mathrm{C}$ for $60 \mathrm{~s}, 50^{\circ} \mathrm{C}$ (for TRPA1) or $56^{\circ} \mathrm{C}$ (for glial fibrillary acidic protein; GFAP) for $45 \mathrm{~s}$, and $72^{\circ} \mathrm{C}$ for $60 \mathrm{~s}$, followed by $72^{\circ} \mathrm{C}$ for $10 \mathrm{~min}$. Primers used were as follows: TRPA1 (5'-GATCTTCGTGTTGCCCTTATTC-3' and $5^{\prime}$-ATAAACACTCCCGTCGATCTC- $\left.{ }^{\prime}\right)$ and GFAP (5'-AGAAAC CAGCCTGGACACCAAA- $3^{\prime}$ and $5^{\prime}$-TGGGAATTGGGCCTAGCAAA CA-3'). Following the PCR, $20 \mu \mathrm{l}$ samples of PCR product were analyzed by agarose gel electrophoresis. The controls were processed identically but lacked reverse transcriptase (these gave no detectable bands on the gels; see Fig. 1).

Field EPSP recordings and induction of LTP. Standard techniques were used as described by us (Carlisle et al., 2008; Moody et al., 2011) to prepare $400 \mu \mathrm{m}$ hippocampal slices from halothane- or isofluraneanesthetized 8- to 18-week-old mice. Slices were maintained in interface type chambers (Fine Science Tools) at $30^{\circ} \mathrm{C}$ in oxygenated $\left(95 \% \mathrm{O}_{2} / 5 \%\right.$ $\mathrm{CO}_{2}$ ) artificial CSF (ACSF) containing the following (in $\mathrm{mm}$ ): $124 \mathrm{NaCl}$, $4.4 \mathrm{KCl}, 25 \mathrm{NaHCO}_{3}, 1 \mathrm{NaH}_{2} \mathrm{PO}_{4}, 2 \mathrm{CaCl}_{2}, 1.2 \mathrm{MgSO}_{4}$, and 10 glucose (flow rate $=2-3 \mathrm{ml} / \mathrm{min}$ ). A bipolar nichrome wire stimulating electrode was placed in stratum radiatum of the hippocampal CA1 region to activate Schaffer collateral fiber synapses onto CA1 pyramidal cells and the resulting field EPSPs (fEPSPs) were recorded using an extracellular glass microelectrode (filled with ACSF; resistance $=5-10 \mathrm{M} \Omega$ placed in stratum radiatum. Presynaptic fibers were stimulated once every $50 \mathrm{~s}$ using a stimulation intensity $(5-11 \mathrm{~V}, 20 \mu \mathrm{s})$ that evoked approximately halfmaximal fEPSPs. LTP was induced using two $1 \mathrm{~s}$ trains of $100 \mathrm{~Hz}$ stimulation (intertrain interval $=10 \mathrm{~s}$ ).

Brain slice whole-cell voltage-clamp recordings. The methods used have been described previously (Carlisle et al., 2008; Moody et al., 2011). Briefly, slices with CA3 region removed were maintained in a submerged slice recording chamber and bathed in a modified ACSF containing picrotoxin $(100 \mu \mathrm{M})$, elevated concentrations of $\mathrm{CaCl}_{2}$ and $\mathrm{MgSO}_{4}(4 \mathrm{mM}$ each), and a lower concentration of $\mathrm{KCl}(2.4 \mathrm{~mm})$. Whole-cell patchclamp recordings were performed with intracellular solution comprising the following (in $\mathrm{mm}$ ): $102 \mathrm{Cs}$ gluconate, $10 \mathrm{~K}$ gluconate, $20 \mathrm{CsCl}, 0.1$ EGTA, 20 HEPES, 10 TEA-Cl, 5 QX-314, 4 Mg-ATP, and 0.3 Tris-GTP,
pH 7.2, osmolarity $295 \mathrm{mOsm}$. The resistance of the pipettes was 4-6 $\mathrm{M} \Omega$. Membrane currents were recorded using pCLAMP 9 software, Axopatch1D amplifier, and Digidata 1322A (Molecular Devices). To examine the AMPA receptor (AMPAR)- and NMDAR-mediated components of the evoked EPSCs, we measured the amplitude of EPSCs recorded at postsynaptic membrane potentials of -80 or $+40 \mathrm{mV}$. The AMPAR-mediated component of the EPSC was measured at the time after EPSC onset corresponding to the peak amplitude of the EPSC at $-80 \mathrm{mV}(\sim 3-5 \mathrm{~ms})$, while the amplitude of the EPSC $50 \mathrm{~ms}$ after onset was used to estimate the NMDAR-mediated component.

Surgery and in vivo microinjections of adeno-associated virus 2/5. Adeno-associated viruses (AAVs) of the $2 / 5$ serotype, using the minimal gfaABC $C_{1} \mathrm{D}$ promoter and capable of expressing the membrane-targeted genetically encoded calcium indicator (GECI) Lck-GCaMP3 specifically within astrocytes, were available from recent studies (Shigetomi et al., 2013). Then 7- to 8-week-old male and female C57BL/6 mice were used in all experiments in accordance with institutional guidelines. All surgical procedures were conducted under general anesthesia using continuous isoflurane (induction at 5\%, maintenance at $1-2.5 \% \mathrm{v} / \mathrm{v}$ ). Depth of anesthesia was monitored continuously and adjusted when necessary. Following induction of anesthesia, the mice were fitted into a stereotaxic frame with their heads secured by blunt ear bars and their noses placed into an anesthesia and ventilation system (David Kopf Instruments). Mice were administered $0.05 \mathrm{ml}$ of buprenorphine (Buprenex; $0.1 \mathrm{mg} /$ $\mathrm{ml}$ ) subcutaneously before surgery. The surgical incision site was then cleaned three times with $10 \%$ povidone iodine and $70 \%$ ethanol. Skin incisions were made, followed by craniotomies of $2-3 \mathrm{~mm}$ in diameter above the left parietal cortex using a small steel burr (Fine Science Tools) powered by a high-speed drill (K.1070; Foredom). Saline $(0.9 \%)$ was applied onto the skull to reduce heating caused by drilling. Unilateral viral injections were performed by using a stereotaxic apparatus (David Kopf Instruments) to guide the placement of beveled glass pipettes (1B100-4; World Precision Instruments) into the left hippocampus (2 $\mathrm{mm}$ posterior to bregma, $1.5 \mathrm{~mm}$ lateral to midline, and $1.6 \mathrm{~mm}$ from the pial surface). Two microliters of AAV2/5 gfaABC ${ }_{1} \mathrm{D}$ Lck-GCaMP3 $\left(1.2 \times 10^{13} \mathrm{gc} / \mathrm{ml}\right)$ was injected by using a syringe pump (Pump11 PicoPlus Elite; Harvard Apparatus). Glass pipettes were left in place for at least $10 \mathrm{~min}$. Surgical wounds were closed with single external 5-0 nylon sutures. Following surgery, animals were allowed to recover overnight in cages placed partially on a low-voltage heating pad. Buprenorphine was administered two times per day for up to $2 \mathrm{~d}$ after surgery. In addition, trimethoprim sulfamethoxazole ( 40 and $200 \mathrm{mg}$, respectively, per $500 \mathrm{ml}$ water) was dispensed in the drinking water for 1 week. Mice were killed $12-20 \mathrm{~d}$ postsurgery for imaging (typically $13-15 \mathrm{~d}$ ). Based on our past experience (Shigetomi et al., 2013), we chose this period since generally it takes $\sim 2$ weeks to achieve GECI expression in cells by AAV infection and because it has been suggested that long-term expression ( $>3$ weeks postAAV injection) can cause toxicity in neurons (Akerboom et al., 2012).

Brain slice astrocyte $\mathrm{Ca}^{2+}$ imaging using Fluo-4. Coronal slices of hippocampus $(300 \mu \mathrm{m})$ of 9 - to 11 -week-old C57BL/6J mice or TRPA1 ${ }^{-1}$ mice were cut in solution comprising (in $\mathrm{mM}$ ): $87 \mathrm{NaCl}, 25 \mathrm{NaHCO}_{3}, 2.5$ $\mathrm{KCl}, 1.25 \mathrm{NaH}_{2} \mathrm{PO}_{4}, 25$ D-glucose, 75 sucrose, $7 \mathrm{MgCl}_{2}$, and $0.5 \mathrm{CaCl}_{2}$ saturated with $95 \% \mathrm{O}_{2}$ and $5 \% \mathrm{CO}_{2}$. Slices were incubated at $\sim 34^{\circ} \mathrm{C}$ for $30 \mathrm{~min}$ and subsequently stored at room temperature in ACSF comprising (in mM): $126 \mathrm{NaCl}, 2.5 \mathrm{KCl}, 1.3 \mathrm{MgCl}_{2}, 10 \mathrm{D}$-glucose, $2.4 \mathrm{CaCl}_{2}, 1.24$ $\mathrm{NaH}_{2} \mathrm{PO}_{4}$, and $26 \mathrm{NaHCO}_{3}$ saturated with $95 \% \mathrm{O}_{2}$ and $5 \% \mathrm{CO}_{2}$. Brain slices were loaded at room temperature in the dark with $5 \mu \mathrm{M}$ Fluo-4/AM (Invitrogen) in ACSF for $60 \mathrm{~min}$, then transferred to dye-free ACSF for at least 30 min before experimentation to allow for cleavage of the AM ester group. Live astrocytes were predominantly loaded with the fluorescent dye with these conditions. This was confirmed by simultaneous acquisition of infrared-differential interference contrast images of astrocytes in the same area. Slices were imaged using an Olympus Fluoview 300 laserscanning confocal microscope with a $20 \mathrm{~mW}$ argon laser, at $<2 \%$ power. Emitted green fluorescence was collected through a 515 long-pass filter. Fluoview software was used for image acquisition. Imaging was performed in the presence of 6-cyano-2,3-dihydroxy-7-nitroquinoxaline $(10 \mu \mathrm{M})$, DL-(-)-2-amino-5-phosphono-pentanoic acid (20 $\mu \mathrm{M})$, bicuculline $(10 \mu \mathrm{M})$, and tetrodotoxin $(1 \mu \mathrm{M})$. We added the same concentra- 
tion of $0.1 \%$ dimethylsulfoxide in the control buffer, when we applied HC 030031.

$D$-Serine biosensor measurements. D-Serine and null biosensor electrodes, $0.5 \mathrm{~mm}$ in length and $50 \mu \mathrm{m}$ in diameter, were purchased from Sarissa Biomedical and used following the manufacturer's instructions (Dale et al., 2005). The biosensor electrodes were mounted on Narishige micromanipulators to allow for manual positioning within hippocampal slices, which were maintained exactly as described above. Changes in electrical potential of the biosensors were measured using a Potentiostat Model 3104 (Pinnacle Technology). Biosensors and null sensors were rehydrated in ACSF before use for $\sim 1 \mathrm{~h}$ and allowed to polarize to +500 $\mathrm{mV}$ over $30 \mathrm{~min}$. Biosensors and null reference sensors were rapidly advanced into the stratum radiatum of CA1. D-Serine biosensor currents were measured by subtracting the current recorded from the reference null biosensor (which lacks D-amino acid oxidase; see Fig. $7 A$ ) from the D-serine biosensor. We only analyzed steady-state D-serine levels within slices, and did not measure the decay of the [D-serine] upon impaling the slices (see Results; Fig. 7C,D). In this regard, our use of the D-serine biosensors to measure steady-state in-slice ambient D-serine concentrations is similar to recent work that measured in-slice adenosine levels (Schmitt et al., 2012). Sensors were calibrated before and after every experiment with $10 \mu \mathrm{M}$ D-serine to measure the sensitivity of the biosensors, and $10 \mu \mathrm{M} 5-\mathrm{HT}$ to check for reaction to nonspecific electro-active compounds. Current changes during the different experimental conditions were compared with the post experiment calibration with the standards. The biosensors were extremely sensitive to, and selective for, $\mathrm{D}$-serine, and responded in a linear manner to varying concentrations of the compound (Fig. $7 B$ ).

Data analysis. Data were analyzed using pCLAMP10 (Molecular Devices), Origin 8 (OriginLab), ImageJ (National Institutes of Health, Bethesda, MD), and GraphPad InStat 3.06 (GraphPad Software). All statistical tests were run in Origin 8 or GraphPad InStat 3.06 using paired or unpaired Student's $t$ tests as appropriate, with significance declared at $p<0.05$, which was indicated by one star in the figures. Significant differences with $p<0.01$ were indicated with two stars in the figures. Origin 8 was also used for creating graphs. Data are as mean \pm SEM from $n$ experiments as indicated in the text (where $n$ is the number of slices for fEPSP and biosensor experiments and the number of cells for patchclamp experiments, as indicated in each of the figures) from between three and eight mice.

Chemicals. All reagents were from VWR, Invitrogen, Sigma-Aldrich, or Ascent Scientific.

\section{Results}

Initial observations on the expression of TRPA1 in astrocytes In our recent studies, we provided evidence for the expression of functional TRPA1 channels in hippocampal astrocytes based on imaging, patch-clamp electrophysiology, siRNA knock-down, knock-out mice, pharmacological screening, TRPA1 selective antagonists, astrocyte-enriched cultures, and Western blot analysis (Shigetomi et al., 2012). This work has now been reviewed and discussed in detail by us and others (Clarke and Attwell, 2012; Tong et al., 2013; Scimemi, 2013). However, we did not perform transcript analysis in the past work and thus began the present study by using RT-PCR to seek to identify TRPA1 transcripts in hippocampal astrocyte enriched cultures. The data shown in Figure 1 show that TRPA1 transcripts were detected in hippocampal astrocytes by RT-PCR, at lower levels than GFAP controls $(p<$ 0.01 unpaired Student's $t$ test; $n=3$ ). Moreover, no transcripts were detected for either TRPA1 or GFAP in samples identically prepared but lacking in reverse transcriptase (Fig. 1). Overall, our RT-PCR data are consistent with recent TRPA1 RT-PCR data for hippocampal astrocytes (Kimura et al., 2013). Together with past work from us (Shigetomi et al., 2012) and others (Kimura et al., 2013) showing functional TRPA1 and TRPA1 protein expression within astrocytes, and with recent immunogold electron microscopy studies showing that TRPA1 channels are localized to astro-
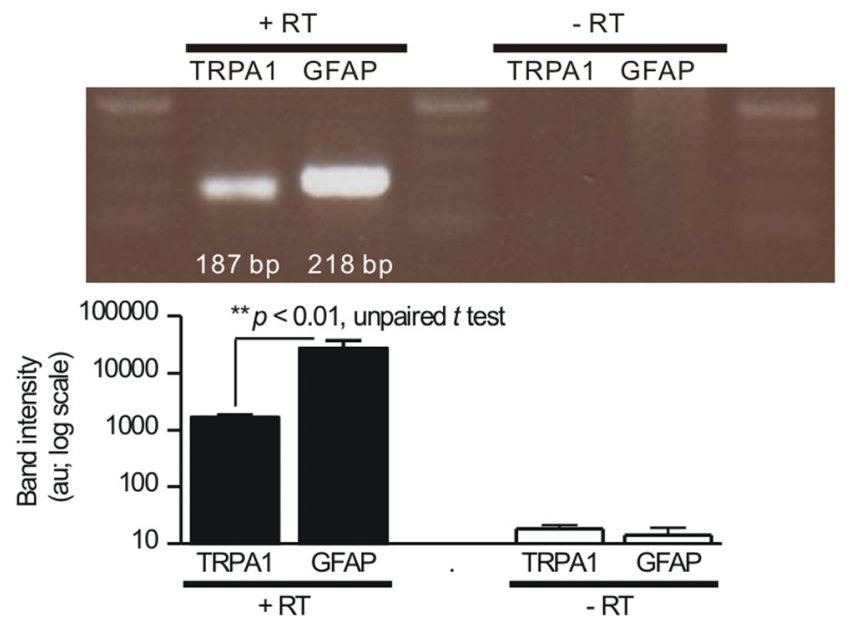

Figure 1. RT-PCR evidence for TRPA1 mRNAs in hippocampal astrocytes. The gel shows the results of RT-PCR experiments for TRPA1 and GFAP (control) with and without reverse transcriptase for mRNA harvested from purified hippocampal astrocytes. The lower bar graph quantifies the results from multiple experiments $(n=3)$.

cyte peripheral processes (Lee et al., 2012), our data show that hippocampal astrocytes also express TRPA1 transcripts (Fig. 1).

We recall that a published gene chip transcriptome database did not find that TRPA1 mRNAs were enriched in astrocytes relative to other cells such as neurons (Cahoy et al., 2008). However, it is important to note that this study only analyzed mRNAs in a population of $\mathrm{S} 100 \beta$-positive astrocytes from entire forebrain (Cahoy et al., 2008). In contrast, the TRPA1 RT-PCR work reported here (Fig. 1) and in published work (Kimura et al., 2013) specifically analyzed all hippocampal astrocytes irrespectively of whether they expressed $S 100 \beta$ or not. This is relevant because of the growing realization that astrocytes represent a genetically and functionally heterogeneous group of cells (Zhang and Barres, 2010; Oberheim et al., 2012).

\section{TRPA1 channels mediate a proportion of microdomain $\mathrm{Ca}^{2+}$ signals in astrocytes}

Astrocyte TRPA1 channel-mediated spotty microdomain $\mathrm{Ca}^{2+}$ signals have been observed using evanescent wave microscopy and membrane-tethered genetically encoded calcium indicators in cultured astrocytes (Shigetomi et al., 2010, 2012). By "spotty," we mean that the signals were localized to microdomains and occurred randomly without any external stimulation. These studies showed that localized microdomain $\mathrm{Ca}^{2+}$ entry via TRPA1 channels dissipated and thus contributed significantly to basal $\mathrm{Ca}^{2+}$ at $\sim 120 \mathrm{nM}$ in cultures and in situ within brain slices of young rodents (Shigetomi et al., 2012). Conversely, blocking TRPA1 reduced basal $\mathrm{Ca}^{2+}$ to $\sim 60 \mathrm{~nm}$. Moreover, within the CA1 region of the hippocampus, functional TRPA1 channels were only detected in astrocytes and not within neurons (Shigetomi et al., 2012). With these studies as a basis, we next determined whether TRPA1 channels contributed to (1) microdomain $\mathrm{Ca}^{2+}$ signals and (2) basal $\mathrm{Ca}^{2+}$ levels of astrocytes in hippocampal slices from adult mice.

TRPA1 channel-mediated microdomain $\mathrm{Ca}^{2+}$ signals cannot be reliably monitored with cytosolic $\mathrm{Ca}^{2+}$ indicator dyes, because these dyes do not enter fine branches and branchlets and/or because the underlying signals are small and most pronounced in near plasma membrane regions (Shigetomi et al., 2010, 2012). However, we showed that TRPA1-mediated signals can be observed using plasma membrane-targeted GECIs (Shigetomi et al., 
2010, 2012). To explore contributions of TRPA1 channels to microdomain $\mathrm{Ca}^{2+}$ signals in astrocytes in situ from adult mice, we used AAVs specifically developed to study near membrane $\mathrm{Ca}^{2+}$ signals in entire astrocytes (Shigetomi et al., 2013). As recently reported during the development and characterization of LckGCaMP3 viruses (Shigetomi et al., 2013), using this approach we measured numerous $\mathrm{Ca}^{2+}$ signals in astrocyte branches. We used the selective TRPA1 blocker HC 030031 (McNamara et al., 2007; Eid et al., 2008) to determine whether any of these were due to TRPA1. As can be seen in the representative traces shown in Figure 2, $A$ and $B$, HC 030031 reduced the numbers of microdomain $\mathrm{Ca}^{2+}$ signals observed in astrocytes. To quantify this result, we analyzed the amplitude $(d F / F)$, half-time $\left(T_{0.5}\right)$, and frequency of the microdomain $\mathrm{Ca}^{2+}$ signals before and during $\mathrm{HC}$ 030031 applications $(80 \mu \mathrm{M})$. We found that HC 030031 significantly reduced the amplitude and frequency of microdomain $\mathrm{Ca}^{2+}$ signals by $\sim 20 \%$ (Fig. $2 C ; n=12$ cells; $p<0.05$ by paired Student's $t$ tests). Thus the peak event $d F / F$ in control and in the presence of $\mathrm{HC} 030031$ was $1.3 \pm 0.03$ and $1.1 \pm 0.02$, respectively $(n=944$ and 598 events, $p<0.01$ with a paired Student's $t$ test). The event frequency for control and in the presence of HC 030031 was $1.4 \pm 0.07$ and $1.0 \pm 0.06$ events $/ \mathrm{min}(n=$ 139 and 120 sites, $p<0.01$ with a paired Student's $t$ test). However, HC 030031 produced no change in the $T_{0.5}$ of the events $(3.6 \pm 0.12$ and $3.6 \pm 0.1 \mathrm{~s}$ for control and in the presence of HC 030031, $n=944$ and 598 events). Further analysis showed that HC 030031 reduced the total number of $\mathrm{Ca}^{2+}$ events measured per cell ( $n=12$ astrocytes; Fig. $2 D$ ), but that this reduction occurred over entire astrocytes and not at a specific distance from the soma (Fig. 2E). This latter result suggests that TRPA1 channels are diffusely expressed throughout astrocyte branches, which is consistent with the uniform distribution of astrocyte branchlets as determined by light and electron microscopy (Shigetomi et al., 2013) and with recent immunogold electron microscopy studies showing TRPA1 in astrocyte processes (Lee et al., 2012). Overall, these data suggest that $\sim 20 \%$ of the spontaneous $\mathrm{Ca}^{2+}$ signals seen within entire astrocytes using Lck-GCaMP3 are due to TRPA1 channels. This number is lower than that previously reported in astrocyte cultures (Shigetomi et al., 2012), but provides strong evidence for functional TRPA1 channels in astrocyte branches.

TRPA1 channels regulate astrocyte basal $\mathrm{Ca}^{2+}$ levels Although TRPA1-mediated microdomain $\mathrm{Ca}^{2+}$ signals can be observed using Lck-GCaMP3, their function is to contribute to astrocyte basal $\mathrm{Ca}^{2+}$ levels as measured with cytosolic organic
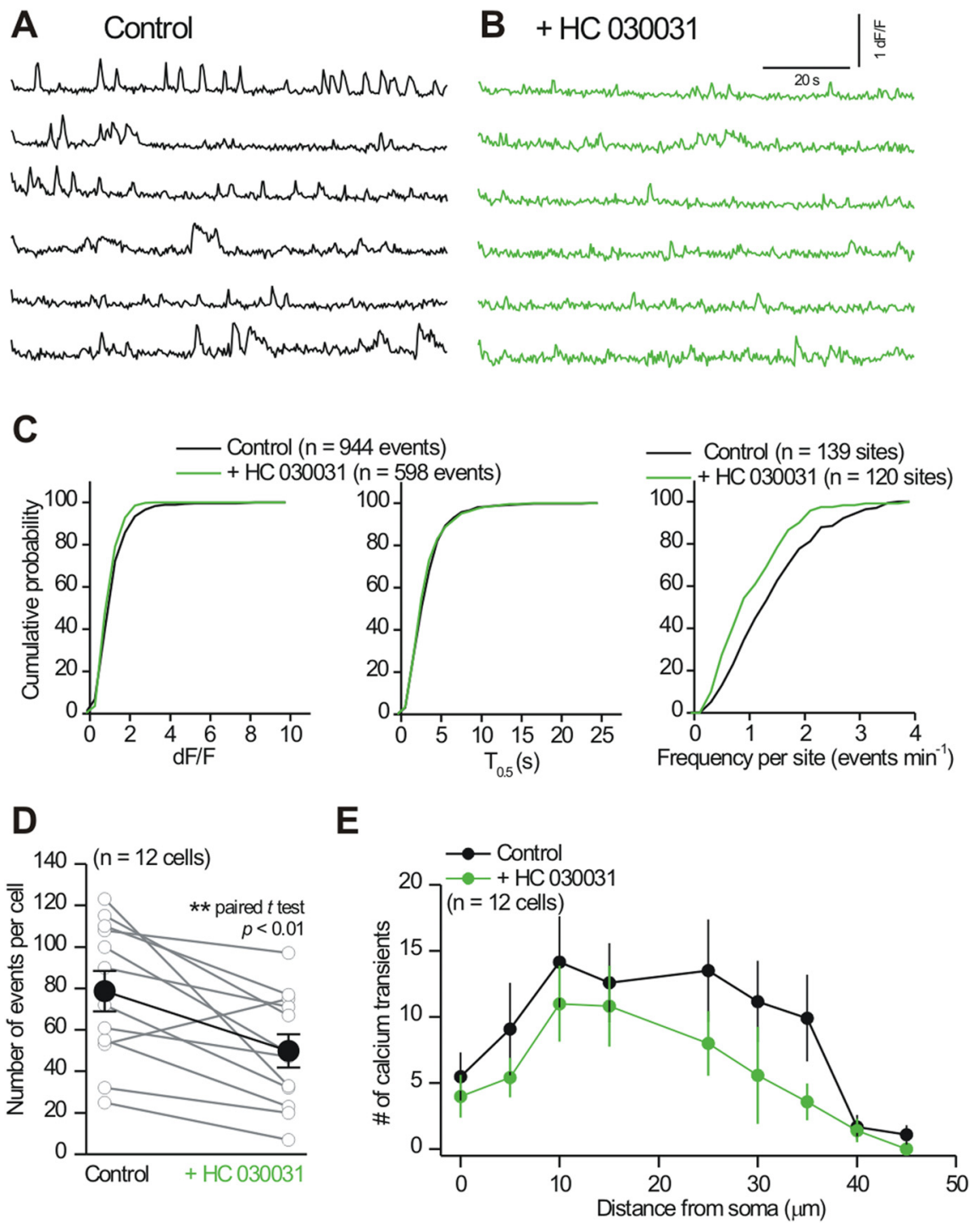

Figure 2. Functional evidence that astrocyte branches express TRPA1 channels that mediate spotty $\mathrm{Ca}^{2+}$ signals. $\boldsymbol{A}$, Representative traces of spontaneous spotty $\mathrm{Ca}^{2+}$ signals recorded from branches of astrocytes expressing Lck-GCaMP3 (Shigetomi et al., 2013). $\boldsymbol{B}$, As in $\boldsymbol{A}$, but in the presence of HC $030031(80 \mu \mathrm{M})$. C, Cumulative probability plots for $\mathrm{Ca}^{2+}$ signal peak heights (dF/F), duration $\left(T_{0.5}\right)$, and frequency. The cumulative probability plots are shifted to smaller amplitudes and lower frequencies in the prese $\mathrm{HC}$ 030031. Note the two distributions are significantly different on the basis of a Kolmogorov-Smirnov test. Averag data are presented in the text. $\boldsymbol{D}$, Scatter plot shows how the number of spotty $\mathrm{Ca}^{2+}$ events measured per astrocyte with from the soma. Note there is a consistent decrease in the number of $\mathrm{Ca}^{2+}$ events measured in the presence of $\mathrm{HC} 030031$ throughout astrocyte territories, implying that the significant decrease shown in $\boldsymbol{E}$ does not occur at any specific distance from the soma. Rather, the HC 030031-sensitive $\mathrm{Ca}^{2+}$ events appear to be drawn from entire astrocytes.

$\mathrm{Ca}^{2+}$ indicator dyes (Shigetomi et al., 2012). Given that a modest $\sim 20 \%$ of the microdomain signals were mediated by TRPA1 channels (Fig. 2), we tested for this possibility in adult slices. To this end, we recorded a baseline period of $5 \mathrm{~min}$ and then applied $80 \mu \mathrm{M} \mathrm{HC} 030031$ in the bath and observed a significant drop in the baseline fluorescence of Fluo-4-loaded astrocytes (Fig. $3 A, B$; $-21 \pm 2 \%, n=42 ; p<0.05$ using a paired Student's $t$ test). This effect of HC 030031 was almost completely abolished in TRPA1 ${ }^{-1-}$ mice (Kwan et al., 2006) as seen in the cumulative probability plots and in the histogram (Fig. $3 B ;-4 \pm 2 \%, n=$ 28; $p<0.01$ using a unpaired Student's $t$ test), indicating that HC 030031 acted via TRPA1 and not via some other mechanism (Shigetomi et al., 2012). These observations in adult mice extend our past work in young mice, and indicate that 
A

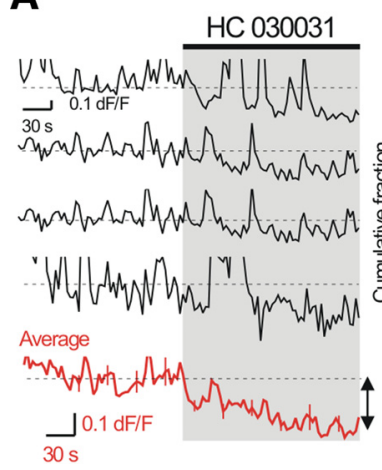

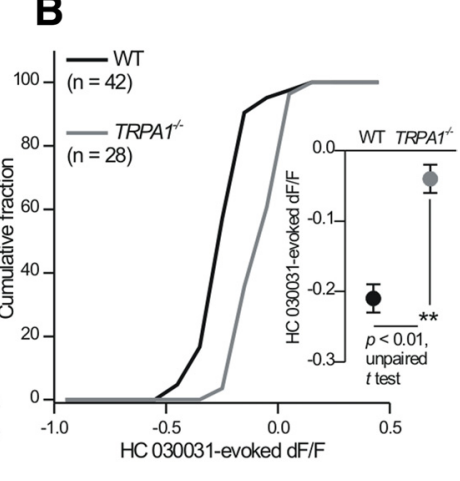

Figure 3. Blocking TRPA1 channels reduces astrocyte basal $\mathrm{Ca}^{2+}$ levels. $A$, Graphs plot $d F / F$ over time from astrocytes loaded with Fluo-4 in hippocampal slices from adult mice. Application of $\mathrm{HC} 030031(80 \mu \mathrm{m})$ reduced the baseline fluorescence of astrocyte somata. Note that in these traces, some of the peaky $\mathrm{Ca}^{2+}$ transients have been clipped to more clearly show the drop in baseline $\mathrm{Ca}^{2+}$. B. Cumulative probability plot of $d F / F$ evoked by HC 030031 applications to astrocytes in acute hippocampal slices from WT and $T R P A 1^{-1-}$ mice. Note the two distributions are significantly different on the basis of a Kolmogorov-Smirnov analysis. The bar graph summarizes the finding that $\mathrm{HC} 030031$ reduces resting $\mathrm{Ca}^{2+}$ levels in astrocytes from WT hippocampal slices.

TRPA1 channels in astrocytes regulate the bulk cytosolic basal $\mathrm{Ca}^{2+}$ concentration of astrocytes (Shigetomi et al., 2012; Tong et al., 2013).

TRPA1 channel blockade reduced LTP and this was rescued by exogenous $\mathrm{D}$-serine

Astrocytes are thought to both constitutively and actively release D-serine. However, the cellular mechanisms that regulate D-serine release are not fully understood (Oliet and Mothet, 2006, 2009; Rusakov et al., 2011; Henneberger et al., 2012). Although activity-dependent D-serine release through $\mathrm{Ca}^{2+}$ dependent mechanisms has been proposed, recent data suggest that $\mathrm{D}$-serine is also released via $\mathrm{Ca}^{2+}$-dependent constitutive release. To explore the potential role of astrocyte TRPA 1 channels, we determined whether HC 030031 affected LTP. We applied HC 03003110 min before and during highfrequency electrical field stimulation of the Schaffer collaterals and monitored fEPSPs for $1 \mathrm{~h}$. HC $030031(80 \mu \mathrm{M})$ significantly suppressed LTP relative to control slices from WT mice at $\sim 52-60 \mathrm{~min}$ postinduction (Fig. $4 A, B$ ). Control fEPSPs were potentiated to $171 \pm 11 \%$ of baseline, whereas in the presence of HC 030031 they were potentiated to $137 \pm 7 \%$ of baseline $(p<0.05$, using unpaired Student's $t$ tests: HC 030031 $n=6$; WT $n=7$ ).

In light of the finding that blocking TRPA1 channels reduces astrocyte $\mathrm{Ca}^{2+}$ levels (Shigetomi et al., 2012) (Fig. $3 A, B$ ), we hypothesized that $\mathrm{Ca}^{2+}$ entry via TRPA1 channels may permit D-serine release (Yang et al., 2003; Henneberger et al., 2010) and hence explain why HC 030031 reduced LTP. This hypothesis linking basal $\mathrm{Ca}^{2+}$ and $\mathrm{D}$-serine release is based on the finding that $\mathrm{Ca}^{2+}$ buffers dialyzed selectively into astrocytes reduce D-serine levels (Henneberger et al., 2010; Kang et al., 2013). Consistent with previous reports (Henneberger et al., 2010), bath applications of D-serine $(10 \mu \mathrm{M})$ did not affect LTP (Fig. $4 C$; $170 \pm 11 \%, n=6, p>0.05$, using unpaired Student's $t$ tests). However, bath applications of D-serine completely blocked the reduction of LTP caused by HC 030031 (Fig. 4B; $173 \pm 15 \%, n=$ $6, p<0.05$, using unpaired Student's $t$ tests). This result demonstrates that the reduction of LTP observed upon blocking TRPA1
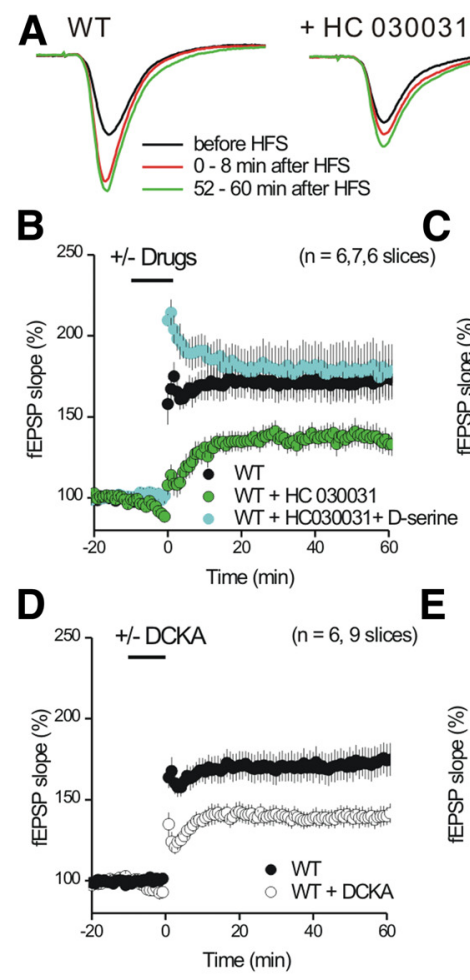

E
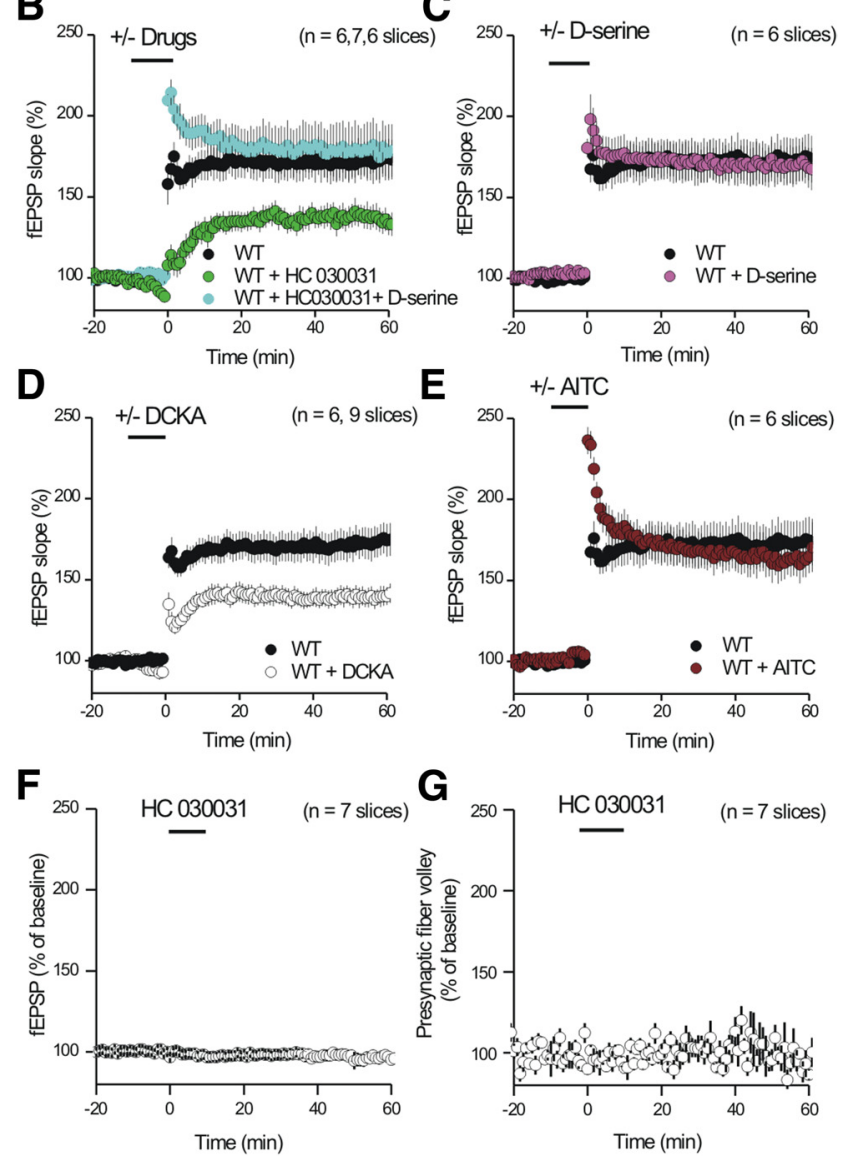

Figure 4. Blocking TRPA1 channels reduces LTP. $A$, fEPSP traces were recorded from the stratum radiatum before and after high-frequency stimulation (HFS; $2 \times 100 \mathrm{~Hz}$, intertrain interval $10 \mathrm{~s}$ ). Traces are shown for several experiments at various time points before and after HFS. $B$, HFS-induced robust LTP in control experiments $(n=7)$. HC $030031(80 \mu \mathrm{m}, n=6)$ suppressed LTP in a manner that was rescued by $10 \mu \mathrm{m}$ D-serine $(n=6)$. C, D-Serine $(10 \mu \mathrm{m})$ did not affect $\operatorname{LTP}(n=6, p=0.876)$. D, The "glycine site" antagonist DCKA $(10 \mu \mathrm{m} ; n=6)$ suppressed LTP E, AITC $(100 \mu \mathrm{m})$ did not affect LTP $(n=$ 7). $\boldsymbol{F}, \mathbf{G}, \mathrm{HC} 030031$ did not affect AMPAR-mediated fEPSPs $(\boldsymbol{F})$ or presynaptic fiber volleys $(\mathbf{G} ; n=7)$.

channels can be rescued by exogenous D-serine, suggesting that TRPA1 channel function in astrocytes permits or causes the constitutive release of substantial amounts of D-serine, which in turn regulates LTP. We further tested this possibility by applying the NMDAR "glycine site" antagonist $10 \mu \mathrm{M}$ 5,7-dichlorokynurenic acid (DCKA) (Yang et al., 2003; Henneberger et al., 2012) and found that it reduced LTP to levels indiscernible from the effect of HC 030031 (Fig. 4D). Together these evaluations strongly suggest that NMDAR-dependent LTP is regulated by endogenous $D$-serine release, which is sensitive to pharmacological block of astrocyte TRPA1 channels (Fig. 4B).

Recent studies using engineered mice show that increasing cytosolic $\mathrm{Ca}^{2+}$ levels within astrocytes does not affect LTP (Agulhon et al., 2010). In light of these data, we applied the TRPA1 agonist allyl isothiocyanate (AITC; $100 \mu \mathrm{M}$ ) to hippocampal slices to determine whether this affected LTP (Shigetomi et al., 2012). Interestingly, we found that AITC increased short-term 
post-tetanic potentiation, but did not affect LTP relative to control (Fig. $4 E ; 163 \pm$ $11 \%, n=6, p>0.05$, using a paired Student's $t$ tests), even though it significantly elevated astrocyte $\mathrm{Ca}^{2+}$ levels in $\sim 40 \%$ of astrocytes (Shigetomi et al., 2012). Consistent with past work on store-mediated $\mathrm{Ca}^{2+}$ elevations (Agulhon et al., 2010), these data suggest that astrocyte $\mathrm{Ca}^{2+}$ elevations triggered by exogenous activation of TRPA1 channels do not detectably regulate $\mathrm{LTP}$.

HC 030031 did not affect either basal fEPSPs or presynaptic fiber volleys (Fig. $4 F, G)$ and did not change CA1 pyramidal neuron resting membrane potentials, membrane resistances, or action potentials (Shigetomi et al., 2012), arguing against effects of this molecule on presynaptic and postsynaptic neurons directly. The available literature also indicates that HC 030031 is a selective TRPA1 antagonist (McNamara et al., 2007; Eid et al., 2008).

TRPA1 ${ }^{-/-}$mice displayed reduced LTP that was rescued by $D$-serine

To further explore roles for TRPA1 channels in regulating LTP, we analyzed TRPA1 $1^{-1-}$ deletion mice (Kwan et al., 2006). We started by examining basal excitatory synaptic transmission and found that the relationship between fEPSP slope and Schaffer collateral stimulation was indiscernible from WT control mice (Fig. $5 A ; n=11$ and 16 for TRPA1 ${ }^{-1-}$ and WT mice, respectively). These data recall past work (Shigetomi et al., 2012) and indicate that basal excitatory synaptic transmission in TRPA1 ${ }^{-/-}$ mice is normal.

We next examined WT and TRPA1 $1^{-/-}$mice and found that LTP was significantly reduced in the knock-out mice (Fig. $5 B, D$; $p<0.01$ using unpaired Student's $t$ tests; $n=12$ and 16 for TRPA1 $1^{-/-}$and WT mice, respectively) to a level comparable to the effect of HC 030031 on WT mice (Fig. 4B). Moreover, LTP in the TRPA $1^{-1-}$ mice was fully rescued to WT levels by the bath application of $10 \mu \mathrm{M}$ D-serine (Fig. $5 C, D ; n=6$ and 5 for TRPA1 $1^{-1-}$ and plus $\mathrm{D}$-serine conditions, respectively). We also determined whether HC 030031 reduced LTP in the TRPA1 ${ }^{-1-}$ mice and found that it did not (Fig. 5D;n= 7 and 6 for TRPA1 $1^{-/-}$and plus HC 030031 conditions, respectively). This latter result is important because it provides strong evidence that the effects of HC 030031 in WT mice (Fig. 4) are due to actions via TRPA1 and not some other mechanism.

Recent studies show that LTP is normal in IP3R2 $2^{-/-}$mice (Agulhon et al., 2010), implying that cytosolic $\mathrm{Ca}^{2+}$ store signals are not crucial for LTP. In accord, we also found that LTP was the same for IP3R2 $2^{-1-}$ and WT littermate control mice (Fig. $5 D ; n=$ 7 and 10 for WT and IP3R2 $2^{-/-}$mice, respectively). Thus our data show that blockade (Fig. 4) or deletion (Fig. 5) of the TRPA1 channel-mediated pathway significantly reduces LTP, but that deletion of the IP3R2-mediated cytosolic store pathway does not, emphasizing how distinct astrocyte $\mathrm{Ca}^{2+}$ sources have separable effects on LTP.
Controls for TRPA1 blockade: ruling out effects of GABA

Recently, we showed that blocking astrocyte TRPA1 channels reduced phasic miniature IPSCs and increased tonic GABA currents onto interneurons of the hippocampus (Shigetomi et al., 2012). The mechanism was reduced GABA transport by astrocyte GAT-3 GABA transporters leading to elevated ambient GABA levels in the extracellular space. As such, the effects of TRPA1 blockade could be mimicked by blocking GAT-3 transporters (Shigetomi et al., 2012). Might this coincidental altered inhibitory interneuron synaptic transmission contribute to the LTP effects (Fig. 4) observed by blocking TRPA1? We considered this unlikely because HC 030031 was only applied for $10 \mathrm{~min}$ in the LTP experiments (Figs. 4, 5) and because the effect on inhibitory synapses was limited to interneurons. Nonetheless, we repeated the LTP experiments with the GAT-3 blocker $\beta$-alanine $(100 \mu \mathrm{M}$; Fig. $6 A, D ; n=5)$, with $5 \mu \mathrm{M}$ GABA in the bath to mimic the effects of elevated tonic GABA levels (Fig. $6 B, D ; n=7$ ) and with both together (Fig. $6 C, D ; n=5$ ). In all three conditions LTP was normal (Fig. 6; $p>0.05$ using unpaired Student's $t$ tests for each pair in Fig. 6D). We suggest, therefore, that the effects of TRPA1 blockade on LTP described in preceding sections (Figs. 4, 5) cannot be accounted for by coincidental effects on inhibitory synapses.

\section{Measuring in situ $\mathrm{D}$-serine levels using D-serine biosensor electrodes}

Since the electrophysiological studies strongly suggest that blockade or deletion of TRPA1 channels reduced the extracellular levels of D-serine, we next sought to measure D-serine levels directly using D-serine biosensor electrodes (Dale et al., 2005) (Fig. 7A; see Materials and Methods). Our calibration experiments show that the biosensor electrodes can reliably detect D-serine levels between 0.4 and $25 \mu \mathrm{M}$ (Fig. $7 B$ ). This sensitivity is appropriate 
A
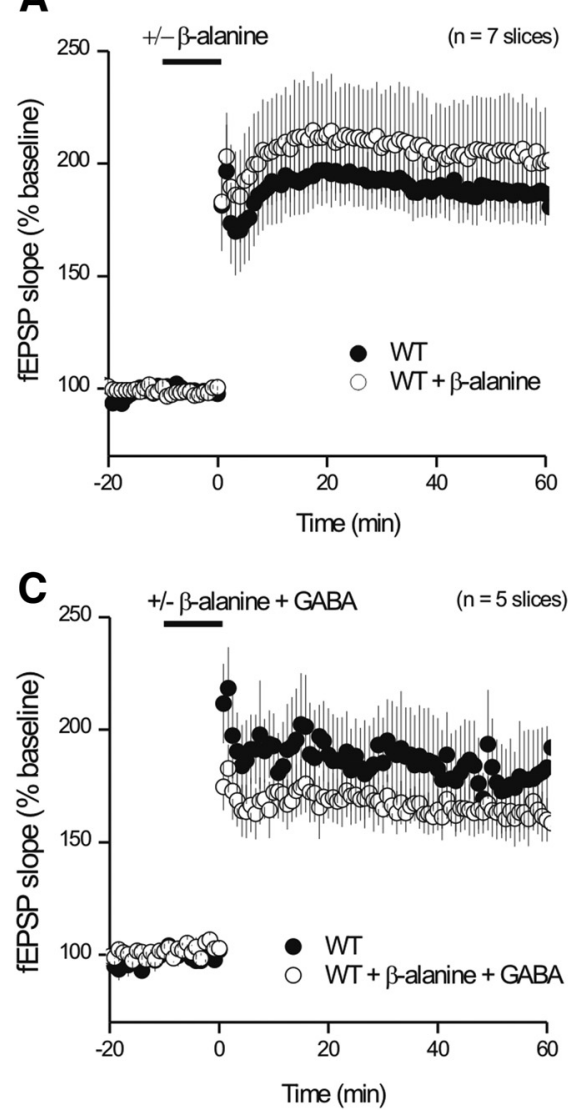

B
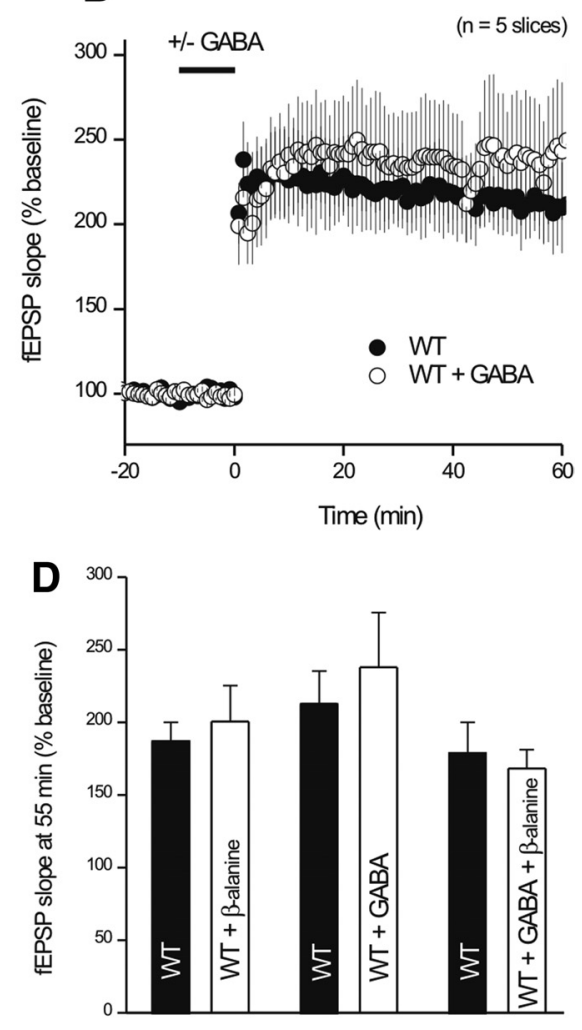

Figure 6. LTP was not altered when GAT-3 was blocked or when GABA was applied in the bath. $\boldsymbol{A}-\boldsymbol{C}$, LTP was normal and indiscernible from WT controls in slices treated with $(\boldsymbol{A})$ the GAT-3 blocker $\beta$-alanine (100 $\mu \mathrm{M}),(\boldsymbol{B}) \mathrm{GABA}(10 \mu \mathrm{M})$, and $(\boldsymbol{C})$ both $\boldsymbol{\beta}$-alanine and GABA together. $\boldsymbol{D}$, Summary bar graph of the findings shown in $\boldsymbol{A}-\boldsymbol{C}$.

for our studies because we expect the amount of $\mathrm{D}$-serine will be $<10 \mu \mathrm{M}$ (Schell, 2004) (Figs. 4B, 5D).

We started with the biosensor electrodes positioned above hippocampal slices. Upon moving the electrode $\sim 200 \mu \mathrm{m}$ into the slice, we measured a large increase in biosensor current, which we converted to D-serine concentration ([D-serine]; Fig. $7 B ; n=8)$. Thus, we measured the "Peak [D-serine] on entering the slice" at $\sim 6 \mu \mathrm{M}$ (Fig. $7 C-E$ ). We associate this transient signal as $\mathrm{D}$-serine release during damage caused by the insertion of the $50 \mu \mathrm{m}$ diameter electrodes. In accord, this rapid increase in [Dserine] declined over minutes and reached a steady-state level in the slice. We estimated this steady-state level by removing the electrode from the slice, providing a measure of "Steady-state [D-serine] in the slice," which was $\sim 1 \mu \mathrm{M}$ (Fig. $7 C ; n=8$ ). We repeated these experiments in TRPA1 $1^{-1-}$ mice $(n=6)$. Representative traces are shown in Fig. $7 D$. By quantifying peak and steady-state [D-serine] levels we found that the peak [D-serine] was not significantly different between WT and TRPA $1^{-/-}$mice, and that HC 030031 application to WT slices did not change peak [D-serine] levels (Fig. 7E; $p>0.05$ using an unpaired Student's $t$ test). In contrast, we found that the steady-state [D-serine] in the slices was significantly lower in TRPA1 ${ }^{-/-}$slices, as well as in WT slices treated with HC 030031 (in relation to control WT slices; Fig. $7 C, D, F ; n=6$ and $7 ; p<0.01$ using an unpaired Student's $t$ test). Together, these data provide strong evidence that the [D-serine] within the slices is $\sim 1 \mu \mathrm{M}$ and that pharmacological block or deletion of TRPA1 significantly reduces this to $\sim 0.4 \mu \mathrm{M}$ (Fig. $7 F$ ).
Synaptic NMDAR/AMPAR ratios are altered when TRPA1 channels are blocked or deleted

Using whole-cell voltage-clamp recording we evaluated how TRPA1 channels contribute to the NMDAR and AMPAR components of evoked EPSCs in pyramidal neurons (measured as the NMDAR/ AMPAR ratio), and measured NMDAR/ AMPAR ratios to cancel the variability of currents between cells. We measured NMDA and AMPA EPSCs simultaneously by varying the holding voltage $(-80 \mathrm{mV}$ for AMPA and $+40 \mathrm{mV}$ for NMDA EPSCs; Fig. $8 A$ ) and explored the roles of TRPA1 channels using HC 030031 in WT mice as well as by comparing between WT and TRPA1 ${ }^{-/-}$ mice. From a control set of recordings, the NMDA/AMPA ratios were $0.015 \pm 0.0045$ and $0.543 \pm 0.027$ at -80 and $+40 \mathrm{mV}$, respectively ( $n=15$ cells). We found that the NMDAR/AMPAR ratio was significantly smaller in TRPA1 $1^{-/-}$mice $(n=17)$ than WT mice $(n=15)$, and that this was restored to WT levels by bath application of D-serine (Fig. $8 B ; n=8 ; p<0.01$ using an unpaired Student's $t$ test). Interestingly, D-serine did not change the NMDAR/ AMPAR ratio in WT mice (Fig. $8 B ; n=8$ ) implying that the "glycine site" of NMDA receptors may be saturated, which recalls data in Figures 4 and 5. Moreover, in WT mice HC 030031 reduced the NMDAR/ AMPAR ratio $(n=9$ from four mice; $p<$ 0.01 using an unpaired Student's $t$ test) and this effect was absent in the TRPA1 $1^{-1-}$ mice $(n=8$ cells from 4 mice; $p>0.05$ using an unpaired Student's $t$ test), confirming that HC 030031 acts via TRPA1 (Fig. 8C). Finally, bath application of D-serine prevented the effects of HC 030031 on WT mice $(n=8)$ and rescued the reduced NMDAR/AMPAR ratio observed in TRPA1 $1^{-/-}$mice back to WT control levels such that HC 030031 was without additional effect (Fig. $8 D ; n=8 ; p>0.05$ using an unpaired Student's $t$ test). Together, these experiments provide compelling evidence that blocking or deleting TRPA1 channels changes the NMDA component of evoked EPSCs recorded from CA1 pyramidal neurons in a D-serine-dependent manner.

\section{Discussion}

The present study was motivated by the recent discovery that hippocampal astrocytes express TRPA1 channels (Shigetomi et al., 2012; Tong et al., 2013; Kimura et al., 2013; Scimemi, 2013) and there are four main findings from it. First, astrocyte TRPA1 channels underlie $\sim 20 \%$ of the ongoing spontaneous $\mathrm{Ca}^{2+}$ microdomain signals (Shigetomi et al., 2013), but contribute significantly to resting basal $\mathrm{Ca}^{2+}$ levels in stratum radiatum region astrocytes from adult mice. Second, blocking or deleting TRPA1 channels reduces NMDAR-dependent LTP in a manner that is dependent on extracellular D-serine levels. Third, blocking or deleting TRPA1 channels reduces extracellular D-serine levels. Fourth, blocking or deleting TRPAl channels reduces the NMDAR component of evoked EPSCs. Overall, our data suggest that astrocyte TRPA1 channels are endogenous regulators of as- 
trocyte D-serine mediated signaling (Mustafa et al., 2004; Oliet and Mothet, 2006, 2009).

We found that activating TRPA 1 channels did not affect LTP, whereas this did result in elevations of astrocyte $\mathrm{Ca}^{2+}$ levels (Shigetomi et al., 2012). A likely explanation may be that close to $\sim 7 \mu \mathrm{M}$ D-serine is normally found in the extracellular fluid, which may be sufficient to nearly saturate hippocampal NMDA receptors (Schell, 2004). If so, elevated astrocyte $\mathrm{Ca}^{2+}$ levels would be inconsequential even if they resulted in additional D-serine release. A further question arises from our work: namely are TRPA1 channels unique or autonomous in their ability to regulate $\mathrm{D}$-serine release? We argue that this is unlikely to be the case. Thus, it is already known that a specific glutamate receptor-mediated molecular cascade is necessary to evoke additional D-serine release from astrocytes (Mothet et al., 2000; Kim et al., 2005) and it is therefore possible that TRPA1 activation failed to cause any more $D$-serine release because the TRPA1 pathway may not activate the requisite signaling machinery within astrocytes. Clearly other parallel pathways regulating $\mathrm{D}$-serine release exist (Mothet et al., 2000; Kim et al., 2005) and TRPA1 channels are not unique in this regard. Broadly, these findings are consistent with data showing that activation of a $\mathrm{Ca}^{2+}$-mobilizing G-protein-coupled receptor that was exogenously expressed within astrocytes, or blocking intracellular store-mediated $\mathrm{Ca}^{2+}$ signals, also did not affect LTP in the hippocampal CA1 region (Agulhon et al., 2010). In contrast, astrocyte $\mathrm{Ca}^{2+}$ elevations mediated by intracellular stores are involved in LTP in the cortex (Takata et al., 2011). What explains these differences? It is likely that brain region-specific differences between the cortex and hippocampus reflect astrocyte diversity in different parts of the brain (Zhang and Barres, 2010; Oberheim et al., 2012). Moreover, empirical data suggest that $D$-serine levels in the cortex are lower than those in the hippocampus and consequently that the glycine site of NMDARs in the cortex may not normally be saturated with D-serine (Fossat et al., 2012). This largely supports the finding that store-mediated $\mathrm{Ca}^{2+}$ signals within astrocytes contribute to D-serine release to regulate cortical LTP (Takata et al., 2011). Along these lines, our data suggest that D-serine levels in the CA1 region of the hippocampus are relatively high, perhaps because astrocytes in this region contain the highest amounts of D-serine (Schell et al., 1997).

Nonetheless, with the aforementioned considerations in mind, in future work it will be important to activate TRPA1 channels with selective agonists and determine whether such manipulations can cause more D-serine release and also affect LTP. At this juncture, these experiments are not possible because no selective TRPA1 agonists exist and the "pungent"
B
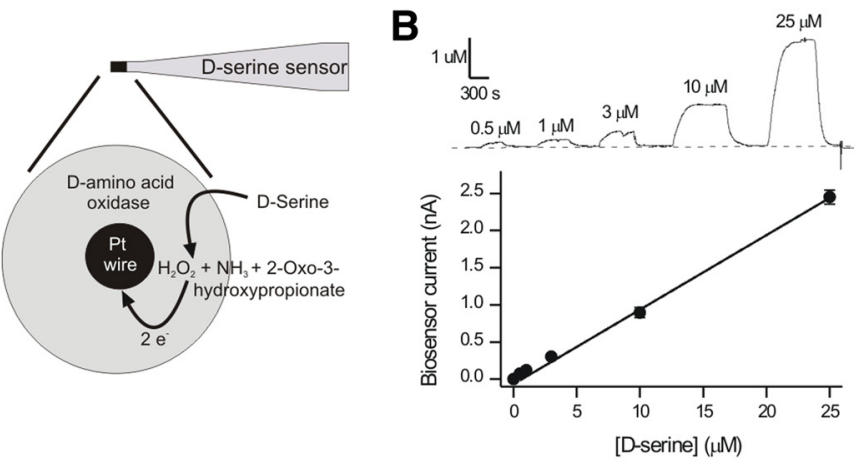

D
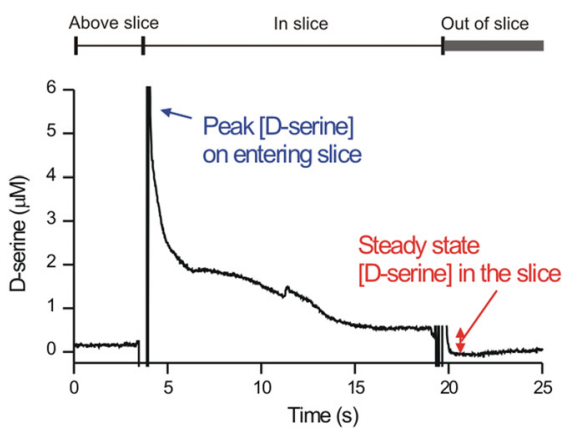

$\mathbf{F}$

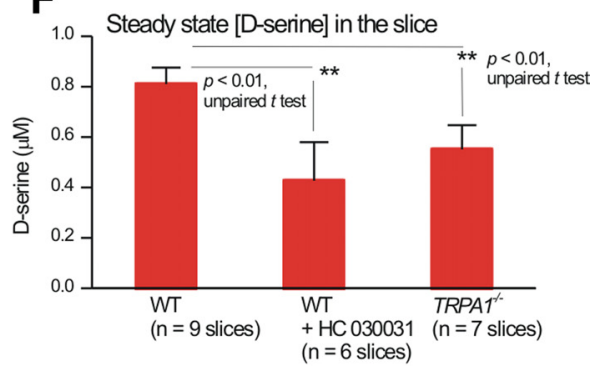

Figure 7. Extracellular D-serine levels are regulated by TRPA1 channel function. $\boldsymbol{A}$, Photograph of a hippocampal slice from a 2-month-old mouse with biosensor electrodes placed in the stratum radiatum. This diagram illustrates how the biosensors work.

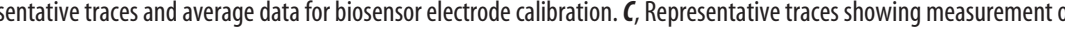
from the slice. This protocol results in two measurements of [D-serine] indicated in blue and red text. $D$, As in $C$, but for recording significant differences. $\boldsymbol{F}$, The bar graph summarizes the steady-state [D-serine] within the slice for three experimental conditions. Note that [D-serine] levels are reduced in WT slices treated with $\mathrm{HC} 030031$ and in slices from $\operatorname{TRPA}^{-/-}$mice.

molecules that nonspecifically activate them have multiple attendant actions (e.g., mustard oil, nicotine, formaldehyde, cinnamon oil, hydrogen sulfide). Specifically, it has been shown that the commonly used TRPA1 agonist AITC (the active substance of mustard oil) still produces responses in TRPA1 deletion mice (Kwan et al., 2006), proving that such molecules are of limited use to explore mechanisms in multicellular preparations such as brain slices, although they are adequate for biophysical studies of recombinant receptors in HEK293 cells and Xenopus oocytes. This is the main reason why we focused on blocking TRPA1 channels with a selective antagonist (HC 030031), and why we also focused on using knock-out mice to explore specific roles for TRPA1 channels. Although cautious, we believe this was the right approach to take. Nonetheless, our findings should be interpreted with all these considerations in mind and, of course, it will be interesting to return to this issue when selective TRPA1 agonists are discovered or synthesized. 
A

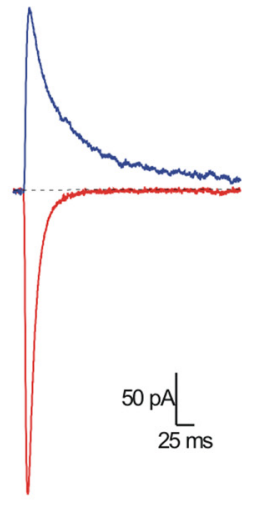

B

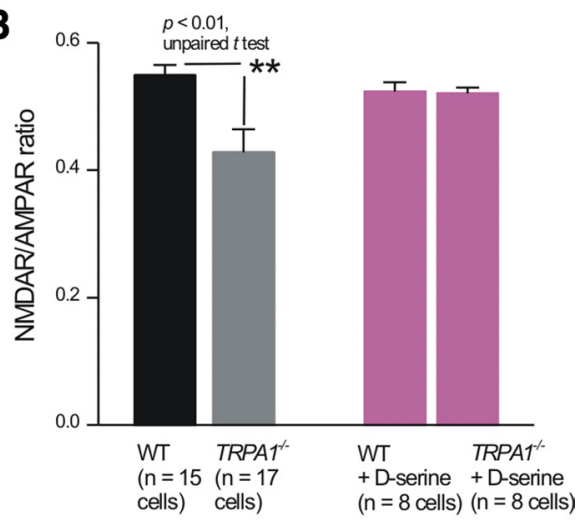

C

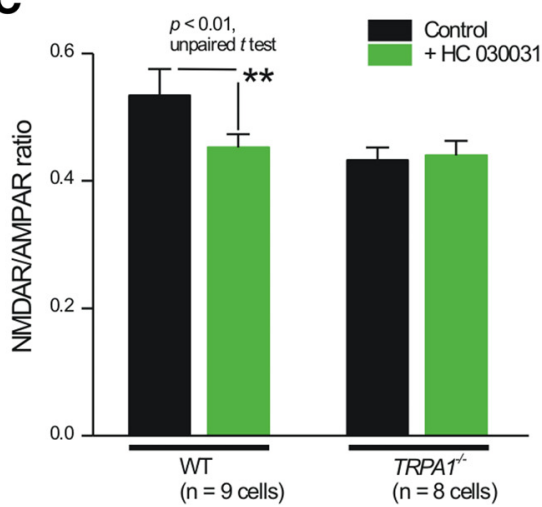

D

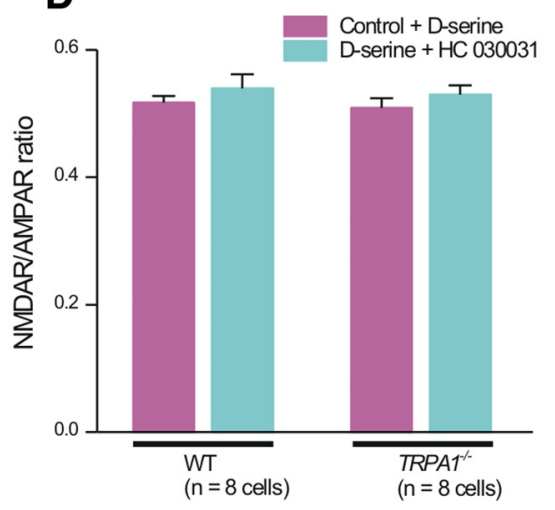

trations measured using biosensor electrodes. As such the $50 \mu \mathrm{m}$ biosensor electrodes provide a measure of ambient D-serine levels in the extracellular fluid rather than at synaptic NMDARs. Consistent with this view, light and electron microscopy shows that NMDAR-expressing synapses are often ensheathed by D-serine containing astrocyte processes (Schell et al., 1995, 1997, 2004), implying that synaptic D-serine concentrations are likely to be higher than those amenable to detection with biosensor electrodes. Nonetheless, our experiments provide strong evidence that blocking or deleting TRPA1 channels reduces extracellular D-serine levels in the hippocampus.

By demonstrating how TRPA1mediated astrocyte basal $\mathrm{Ca}^{2+}$ levels regulate LTP via D-serine release and confirming that intracellular store signals do not (Agulhon et al., 2010), our studies highlight the importance of studying the full diversity of astrocyte $\mathrm{Ca}^{2+}$ signals in relation to their potential physiological roles. As such, it will be important to embrace and rigorously explore the concept of astrocyte heterogeneity and calcium signal diversity (Zhang and Barres, 2010; Oberheim et al., 2012) in future experiments in situ and in vivo. From this perspective, our study builds on recent work demonstrating the existence of distinct types of $\mathrm{Ca}^{2+}$ signals in Bergmann glia (Nimmerjahn et al., 2009) and work showing that quantifiably similar $\mathrm{Ca}^{2+}$ signals have distinct downstream consequences in cell culture and in situ (Bowser and Khakh, 2007; Shigetomi et al., 2008). Clearly then, $\mathrm{Ca}^{2+}$ does not appear to be an all-or-none binary signal within astrocytes (Tong et al., 2013) and perhaps there is little contradiction in past studies that

In future studies, it will be interesting to delete TRPA1 channels from all as well as specific subpopulations of hippocampal astrocytes and explore synaptic plasticity using the experimental approaches and controls reported herein. However, at this juncture such experiments are not possible and at least two advances are needed for them to commence. First, a knock-in mouse line expressing a floxed allele of TRPA1, in which key exons are flanked by loxP sites, needs to be generated and rigorously characterized. Second, genetic strategies are needed to selectively express and inducibly activate Cre recombinase within astrocytes. We endeavor to develop the appropriate genetic tools and return to this issue in the years ahead.

We found that blocking or deleting TRPA1 channels significantly reduced NMDAR-dependent LTP and the NMDA component of evoked EPSCs in a manner that was completely rescued by exogenous D-serine. Moreover, blocking or genetically deleting TRPA1 channels also reduced the concentration of D-serine within brain slices, providing strong evidence that TRPA1 channels regulate D-serine release. However, a note of caution is necessary when precisely interpreting absolute D-serine concen- have explored distinct aspects of astrocyte $\mathrm{Ca}^{2+}$ signaling in relation to LTP (Agulhon et al., 2010; Henneberger et al., 2010).

In summary, the recent discovery and molecular identity of an astrocyte transmembrane $\mathrm{Ca}^{2+}$ flux pathway mediated by TRPA1 channels provided a new opportunity for exploring the role of astrocytes in synaptic plasticity (Henneberger et al., 2010). Overall, our findings show that TRPA1 channels are expressed in adult astrocytes where they contribute markedly to resting intracellular $\mathrm{Ca}^{2+}$ levels. Importantly, basal, but not elevated, TRPA1-mediated astrocyte $\mathrm{Ca}^{2+}$ levels are important for NMDARdependent forms of LTP in the hippocampus, because they appear to passively drive the release of the D-serine (Schell et al., 1995, 1997). Such a pathway has not been considered in past astrocyte studies (Agulhon et al., 2008), which have focused on elevations due to intracellular store-mediated $\mathrm{Ca}^{2+}$ release (Agulhon et al., 2008, 2010). In contrast, the data reported herein and in our past work (Shigetomi et al., 2012) suggest that the basal $\mathrm{Ca}^{2+}$ concentration of astrocytes is important to control what appear to be homeostatic functions (Tong et al., 2013). Thus, in the present study we show that astrocyte TRPA1 channels regulate 
constitutive D-serine release, whereas previously we showed that they also regulate GABA uptake (Shigetomi et al., 2012; Tong et al., 2013). However, both these mechanisms contribute significantly to neuronal function, albeit in a neuromodulatory capacity. Along with gliotransmission (Haydon, 2001; Halassa and Haydon, 2010), these findings emphasize the diversity of mechanisms that astrocytes may use to control/regulate neurons and microcircuits.

Interestingly, past work has shown that the basal $\mathrm{Ca}^{2+}$ level of astrocytes is significantly elevated in models of Alzheimer's disease (Kuchibhotla et al., 2009). It will thus be interesting to extend our studies and evaluate if TRPA1 channel fluxes, and the ensuing downstream neuronal consequences, contribute to cognition (Turpin et al., 2011), traumatic injury (Mustafa et al., 2010), and brain disorders (Basu et al., 2009; Nedergaard et al., 2010), circumstances in which D-serine is thought to be involved (Mustafa et al., 2004). If so, astrocyte TRPA1 channels may be valuable therapeutic targets for brain disorders.

\section{References}

Agulhon C, Petravicz J, McMullen AB, Sweger EJ, Minton SK, Taves SR, Casper KB, Fiacco TA, McCarthy KD (2008) What is the role of astrocyte calcium in neurophysiology? Neuron 59:932-946. CrossRef Medline

Agulhon C, Fiacco TA, McCarthy KD (2010) Hippocampal short- and longterm plasticity are not modulated by astrocyte $\mathrm{Ca} 2+$ signaling. Science 327:1250-1254. CrossRef Medline

Akerboom J, Chen TW, Wardill TJ, Tian L, Marvin JS, Mutlu S, Calderón NC, Esposti F, Borghuis BG, Sun XR, Gordus A, Orger MB, Portugues R, Engert F, Macklin JJ, Filosa A, Aggarwal A, Kerr RA, Takagi R, Kracun S, et al. (2012) Optimisation of a GCaMP calcium indicator for neural activity imaging. J Neurosci 32:13819-13840. CrossRef Medline

Barres BA (2008) The mystery and magic of glia: a perspective on their roles in health and disease. Neuron 60:430-440. CrossRef Medline

Basu AC, Tsai GE, Ma CL, Ehmsen JT, Mustafa AK, Han L, Jiang ZI, Benneyworth MA, Froimowitz MP, Lange N, Snyder SH, Bergeron R, Coyle JT (2009) Targeted disruption of serine racemase affects glutamatergic neurotransmission and behavior. Mol Psychiatry 14:719-727. CrossRef Medline

Bowser DN, Khakh BS (2007) Two forms of single vesicle astrocyte exocytosis imaged with total internal reflection fluorescence microscopy. Proc Natl Acad Sci U S A 104:4212-4217. CrossRef Medline

Bushong EA, Martone ME, Jones YZ, Ellisman MH (2002) Protoplasmic astrocytes in CA1 stratum radiatum occupy separate anatomical domains. J Neurosci 22:183-192. Medline

Cahoy JD, Emery B, Kaushal A, Foo LC, Zamanian JL, Christopherson KS, Xing Y, Lubischer JL, Krieg PA, Krupenko SA, Thompson WJ, Barres BA (2008) A transcriptome database for astrocytes, neurons, and oligodendrocytes: a new resource for understanding brain development and function. J Neurosci 28:264-278. CrossRef Medline

Carlisle HJ, Fink AE, Grant SG, O’Dell TJ (2008) Opposing effects of PSD-93 and PSD-95 on long-term potentiation and spike timingdependent plasticity. J Physiol 586:5885-5900. CrossRef Medline

Clarke LE, Attwell D (2012) An astrocyte TRP switch for inhibition. Nat Neurosci 15:3-4. CrossRef Medline

Dale N, Hatz S, Tian F, Llaudet E (2005) Listening to the brain: microelectrode biosensors for neurochemicals. Trends Biotechnol 23:420-428. CrossRef Medline

DeFelipe J (2010) Cajal's butterflies of the soul: science and art. New York: Oxford UP

Eid SR, Crown ED, Moore EL, Liang HA, Choong KC, Dima S, Henze DA, Kane SA, Urban MO (2008) HC-030031, a TRPA1 selective antagonist, attenuates inflammatory- and neuropathy-induced mechanical hypersensitivity. Mol Pain 4:48. CrossRef Medline

Fossat P, Turpin FR, Sacchi S, Dulong J, Shi T, Rivet JM, Sweedler JV, Pollegioni L, Millan MJ, Oliet SH, Mothet JP (2012) Glial D-serine gates NMDA receptors at excitatory synapses in prefrontal cortex. Cereb Cortex 22:595-606. CrossRef Medline

Halassa MM, Haydon PG (2010) Integrated brain circuits: astrocytic networks modulate neuronal activity and behavior. Annu Rev Physiol 72: 335-355. CrossRef Medline
Halassa MM, Fellin T, Takano H, Dong JH, Haydon PG (2007) Synaptic islands defined by the territory of a single astrocyte. J Neurosci 27:64736477. CrossRef Medline

Hashimoto A, Nishikawa T, Oka T, Takahashi K (1993) Endogenous $\mathrm{D}$-serine in rat brain: $\mathrm{N}$-methyl-D-aspartate receptor-related distribution and aging. J Neurochem 60:783-786. CrossRef Medline

Haydon PG (2001) GLIA: listening and talking to the synapse. Nat Rev Neurosci 2:185-193. CrossRef Medline

Henneberger C, Papouin T, Oliet SH, Rusakov DA (2010) Long-term potentiation depends on release of D-serine from astrocytes. Nature 463: 232-236. CrossRef Medline

Henneberger C, Bard L, Rusakov DA (2012) D-Serine: a key to synaptic plasticity? Int J Biochem Cell Biol 44:587-590. CrossRef Medline

Kang N, Peng H, Yu Y, Stanton PK, Guilarte TR, Kang J (2013) Astrocytes release D-serine by a large vesicle. Neuroscience 240:243-257. CrossRef Medline

Kim PM, Aizawa H, Kim PS, Huang AS, Wickramasinghe SR, Kashani AH, Barrow RK, Huganir RL, Ghosh A, Snyder SH (2005) Serine racemase: activation by glutamate neurotransmission via glutamate receptor interacting protein and mediation of neuronal migration. Proc Natl Acad Sci U S A 102:2105-2110. CrossRef Medline

Kimura Y, Mikami Y, Osumi K, Tsugane M, Oka JI, Kimura H (2013) Polysulfides are possible $\mathrm{H} 2 \mathrm{~S}$-derived signaling molecules in rat brain. FASEB J. Advance online publication. Retrieved Feb. 14, 2013. doi: 10.1096/fj.12226415. CrossRef Medline

Kirchhoff F (2010) Neuroscience. Questionable calcium. Science 327: 1212-1213. CrossRef Medline

Kuchibhotla KV, Lattarulo CR, Hyman BT, Bacskai BJ (2009) Synchronous hyperactivity and intercellular calcium waves in astrocytes in Alzheimer mice. Science 323:1211-1215. CrossRef Medline

Kwan KY, Allchorne AJ, Vollrath MA, Christensen AP, Zhang DS, Woolf CJ, Corey DP (2006) TRPA1 contributes to cold, mechanical, and chemical nociception but is not essential for hair-cell transduction. Neuron 50 : 277-289. CrossRef Medline

Lee SM, Cho YS, Kim TH, Jin MU, Ahn DK, Noguchi K, Bae YC (2012) An ultrastructural evidence for the expression of transient receptor potential ankyrin 1 (TRPA1) in astrocytes in the rat trigeminal caudal nucleus. J Chem Neuroanat 45:45-49. CrossRef Medline

Li X, Zima AV, Sheikh F, Blatter LA, Chen J (2005) Endothelin-1-induced arrhythmogenic Ca2 + signaling is abolished in atrial myocytes of inositol-1,4,5-trisphosphate(IP3)-receptor type 2-deficient mice. Circ Res 96:1274-1281. CrossRef Medline

McNamara CR, Mandel-Brehm J, Bautista DM, Siemens J, Deranian KL, Zhao M, Hayward NJ, Chong JA, Julius D, Moran MM, Fanger CM (2007) TRPA1 mediates formalin-induced pain. Proc Natl Acad Sci U S A 104:13525-13530. CrossRef Medline

Moody TD, Watabe AM, Indersmitten T, Komiyama NH, Grant SG, O’Dell TJ (2011) Beta-adrenergic receptor activation rescues theta frequency stimulation-induced LTP deficits in mice expressing C-terminally truncated NMDA receptor GluN2A subunits. Learn Mem 18:118-127. CrossRef Medline

Mothet JP, Parent AT, Wolosker H, Brady RO Jr, Linden DJ, Ferris CD, Rogawski MA, Snyder SH (2000) D-serine is an endogenous ligand for the glycine site of the N-methyl-D-aspartate receptor. Proc Natl Acad Sci U S A 97:4926-4931. CrossRef Medline

Mustafa AK, Kim PM, Snyder SH (2004) D-Serine as a putative glial neurotransmitter. Neuron Glia Biol 1:275-281. Medline

Mustafa AK, Ahmad AS, Zeynalov E, Gazi SK, Sikka G, Ehmsen JT, Barrow RK, Coyle JT, Snyder SH, Doré S (2010) Serine racemase deletion protects against cerebral ischemia and excitotoxicity. J Neurosci 30:14131416. CrossRef Medline

Nagai Y, Tsugane M, Oka J, Kimura H (2004) Hydrogen sulfide induces calcium waves in astrocytes. FASEB J 18:557-559. Medline

Nedergaard M, Verkhratsky A (2012) Artifact versus reality-How astrocytes contribute to synaptic events? Glia 60:1013-1023. CrossRef Medline

Nedergaard M, Rodríguez JJ, Verkhratsky A (2010) Glial calcium and diseases of the nervous system. Cell Calcium 47:140-149. CrossRef Medline Nimmerjahn A, Mukamel EA, Schnitzer MJ (2009) Motor behavior activates Bergmann glial networks. Neuron 62:400-412. CrossRef Medline

Oberheim NA, Goldman SA, Nedergaard M (2012) Heterogeneity of astrocytic form and function. Methods Mol Biol 814:23-45. CrossRef Medline Oliet SH, Mothet JP (2006) Molecular determinants of D-serine-mediated 
gliotransmission: from release to function. Glia 54:726-737. CrossRef Medline

Oliet SH, Mothet JP (2009) Regulation of N-methyl-D-aspartate receptors by astrocytic D-serine. Neuroscience 158:275-283. CrossRef Medline

Papouin T, Ladépêche L, Ruel J, Sacchi S, Labasque M, Hanini M, Groc L, Pollegioni L, Mothet JP, Oliet SH (2012) Synaptic and extrasynaptic NMDA receptors are gated by different endogenous coagonists. Cell 150: 633-646. CrossRef Medline

Rusakov DA, Zheng K, Henneberger C (2011) Astrocytes as regulators of synaptic function: a quest for the $\mathrm{Ca} 2+$ master key. Neuroscientist 17: 513-523. CrossRef Medline

Schell MJ (2004) The N-methyl D-aspartate receptor glycine site and D-serine metabolism: an evolutionary perspective. Philos Trans R Soc Lond B Biol Sci 359:943-964. CrossRef Medline

Schell MJ, Molliver ME, Snyder SH (1995) D-serine, an endogenous synaptic modulator: localization to astrocytes and glutamate-stimulated release. Proc Natl Acad Sci U S A 92:3948-3952. CrossRef Medline

Schell MJ, Brady RO Jr, Molliver ME, Snyder SH (1997) D-serine as a neuromodulator: regional and developmental localizations in rat brain glia resemble NMDA receptors. J Neurosci 17:1604-1615. Medline

Schmitt LI, Sims RE, Dale N, Haydon PG (2012) Wakefulness affects synaptic and network activity by increasing extracellular astrocyte-derived adenosine. J Neurosci 32:4417-4425. CrossRef Medline

Scimemi A (2013) A TRP among the astrocytes. J Physiol 591:9-15. CrossRef Medline

Shigetomi E, Khakh BS (2009) Measuring near plasma membrane and global intracellular calcium dynamics in astrocytes. J Vis Exp 26. pii: 1142. CrossRef Medline

Shigetomi E, Bowser DN, Sofroniew MV, Khakh BS (2008) Two forms of astrocyte calcium excitability have distinct effects on NMDA receptormediated slow inward currents in pyramidal neurons. J Neurosci 28: 6659-6663. CrossRef Medline

Shigetomi E, Kracun S, Sofroniew MV, Khakh BS (2010) A genetically tar- geted optical sensor to monitor calcium signals in astrocyte processes. Nat Neurosci 13:759-766. CrossRef Medline

Shigetomi E, Tong X, Kwan KY, Corey DP, Khakh BS (2012) TRPA1 channels regulate astrocyte resting calcium and inhibitory synapse efficacy through GAT-3. Nat Neurosci 15:70-80. CrossRef Medline

Shigetomi E, Bushong EA, Haustein MD, Tong X, Jackson-Weaver O, Kracun S, Xu J, Sofroniew MV, Ellisman MH, Khakh BS (2013) Imaging calcium microdomains within entire astrocyte territories and endfeet with GCaMPs expressed using adeno-associated viruses. J Gen Physiol 141: 633-647. CrossRef Medline

Takata N, Mishima T, Hisatsune C, Nagai T, Ebisui E, Mikoshiba K, Hirase H (2011) Astrocyte calcium signaling transforms cholinergic modulation to cortical plasticity in vivo. J Neurosci 31:18155-18165. CrossRef Medline

Tong X, Shigetomi E, Looger LL, Khakh BS (2013) Genetically encoded calcium indicators and astrocyte calcium microdomains. Neuroscientist 19:274-291. CrossRef Medline

Turpin FR, Potier B, Dulong JR, Sinet PM, Alliot J, Oliet SH, Dutar P, Epelbaum J, Mothet JP, Billard JM (2011) Reduced serine racemase expression contributes to age-related deficits in hippocampal cognitive function. Neurobiol Aging 32:1495-1504. CrossRef Medline

Ventura R, Harris KM (1999) Three-dimensional relationships between hippocampal synapses and astrocytes. J Neurosci 19:6897-6906. Medline

Wolosker H, Blackshaw S, Snyder SH (1999) Serine racemase: a glial enzyme synthesizing D-serine to regulate glutamate- $\mathrm{N}$-methyl-D-aspartate neurotransmission. Proc Natl Acad Sci U S A 96:13409-13414. CrossRef Medline

Yang Y, Ge W, Chen Y, Zhang Z, Shen W, Wu C, Poo M, Duan S (2003) Contribution of astrocytes to hippocampal long-term potentiation through release of D-serine. Proc Natl Acad Sci USA 100: 15194-15199. CrossRef Medline

Zhang Y, Barres BA (2010) Astrocyte heterogeneity: an underappreciated topic in neurobiology. Curr Opin Neurobiol 20:588-594. CrossRef Medline 